\title{
VIOLENCIA E INSEGURIDAD EN MÉXICO: NECESIDAD DE UN PARTEAGUAS CIVILIZATORIO
}

\author{
Humberto Márquez Covarrubias* \\ Raúl Delgado Wise** \\ Rodolfo García Zamora***
}

\section{Resumen}

El modelo de acumulación vigente en México desde los años ochenta del siglo pasado ha concentrado poder y riqueza. Mientras que las grandes corporaciones nacionales y multinacionales succionan el excedente económico generado por la conjunción de múltiples esfuerzos sociales e institucionales, una guerra emprendida contra el mundo del trabajo desmantela el sistema de subsistencia social, erosiona el fondo de vida proletario, desmantela el Estado social, canaliza enormes recursos fiscales al sector corporativo y depreda las bases materiales de la producción. El sistema de poder constriñe la noción de democracia a la órbita electoral, pero sin permitir el ascenso de opciones partidarias que, eventualmente, propongan un proyecto posneoliberal. Ante la indignación social y la pérdida de legitimidad, la "guerra contra el narcotráfico", tutelada por la estrategia de seguridad estadounidense, genera un clima social de realismo salvaje que criminaliza a los sectores excluidos y pobres, además de que propaga el miedo y la esquizofrenia colectiva como medida encubierta de control social. La descomposición social generalizada pone en la palestra la necesidad de un cambio estructural que atisbe un horizonte civilizatorio basado en la democracia, la equidad, el buen vivir y la justicia social.

Palabras clave: violencia, inseguridad, insustentabilidad, desarrollo, México.

* Responsable del Programa de Doctorado en Estudios del Desarrollo de la Universidad Autónoma de Zacatecas.

** Director de la Unidad Académica en Estudios del Desarrollo de la Universidad Autónoma de Zacatecas.

*** Docente-investigador de la Unidad Académica en Estudios del Desarrollo de la Universidad Autónoma de Zacatecas. 


\section{Abstract}

The model of accumulation that has been in effect in Mexico since the 1980s has concentrated capital, power and wealth. While large national and multinational corporations suck up the economic surplus generated by a combination of multiple social and institutional efforts, a war waged against the working world dismantles the social-subsistence system, erodes the proletariat's life-fund, dismantles the welfare State, channels enormous fiscal resources to the corporate sector and plunders the material basis of production. The existing power structure restricts the notion of democracy to the electoral orbit, without allowing for the rise of options in the form of political parties that occasionally propose a post-neoliberal project. In a context of social indignation and loss of legitimacy, the "war on drugs", carried out under the aegis of the United States' security strategy, has created a social climate of savage realism that criminalizes the poor and the excluded sectors, besides spreading fear and collective schizophrenia. This general social breakdown puts the spotlight on the need for structural change oriented toward democracy, equity, "good living" and social justice.

Keywords: violence, insecurity, unsustainability, development, Mexico. 


\section{INTRODUCCIÓN}

$\mathrm{E}$ pensamiento convencional subyacente al modelo de desarrollo neoliberal, impuesto en México hace tres décadas, pregona que las políticas de ajuste estructural y los tratados de libre comercio configuraran procesos de convergencia económica en América del Norte. Abandonada la tentativa de desarrollo nacional basado en la industrialización, el mercado interno y el bienestar social, los sectores económicos estratégicos rentables son entregados a las grandes corporaciones, nacionales y multinacionales, bajo el ardid de que fungirán como agentes difusores del progreso tecnológico, el crecimiento económico y la prosperidad. El modelo neoliberal tiene el doble cometido de ampliar los ámbitos de valorización para el capital corporativo e incrementar el poder de clase de las élites nacionales y transnacionales.

El proceso de neoliberalización hace eclosión al influjo de los organismos financieros internacionales que imponen el programa shock como respuesta a la "crisis de la deuda", sin necesidad de una asonada militar, pero tampoco sin consulta popular o como resultado de un proceso electoral que legitimara dicho programa. Desde las altas esferas del poder se ejecuta un virtual golpe de Estado técnico, merced al férreo control político estatal y a la hegemonía del Partido Revolucionario Institucional (PRI). Al tiempo en que desmantela la estructura del precario Estado social y su pacto nacional-populista, el gobierno teje un nuevo corporativismo basado en la unción de intereses del gran capital y el poder político; los sectores obrero y popular resultan relegados de la nueva coalición. Los principales sectores y empresas de la economía nacional son cedidos a empresarios afines al régimen político, con lo que se gesta una camada de nuevos magnates y aflora una etapa económica centrada en los monopolios.

Lejos de insertarse estratégicamente al mercado mundial, la organización económica está confinada en la peor de las competitividades conocidas, la "espuria", es decir, aquella basada en la superexplotación del trabajo, el extractivismo de recursos naturales y la financiarización. La reestructuración neoliberal implica el desmantelamiento y desarticulación de la economía doméstica y 
su reinserción, asimétrica y subordinada, en la órbita del capitalismo internacional y particularmente estadounidense. Se trata, en el fondo, de una embestida brutal contra las clases trabajadoras, incluyendo el despojo y apropiación de recursos naturales, así como la destrucción de capital "nacional". Esta situación, asociada a las estrategia de internacionalización del capital comandadas por las grandes corporaciones multinacionales en mancuerna con una fracción limitada de la élite política y empresarial mexicana, deriva en la emergencia de nuevos y más atroces mecanismos de transferencia de excedentes, que limitan sobremanera la capacidad de acumulación nacional y profundizan la condición periférica y dependiente del país en el concierto capitalista global (Márquez y Delgado Wise, 2011).

El sistema de dominación imperante constriñe la noción de democracia al plano electoral, donde incluso el sufragio efectivo puede ser esquilmado, y, en el peor de los casos, el modelo económico-político se remacha con la implementación de estrategias coercitivas y punitivas amparadas en la "guerra contra el narcotráfico", acorde a la política de seguridad nacional del decadente imperio estadounidense, que ejerce un pernicioso control político sobre la población inerme, cuyo estela fúnebre también abarca la criminalización de jóvenes e infantes, especialmente de los pobres y excluidos.

\section{NEOLIBERALIZACIÓN: FUENTE DE GANANCIAS ESPURIAS}

El capitalismo neoliberal desencadena un cúmulo de violencias sistémicas y emergentes. Las violencias sistémicas están enraizadas en el funcionamiento del patrón de acumulación y el sistema de poder. Los agentes principales de este tipo de violencias son el capital y el Estado. Las prácticas violentes de estos agentes se ejercen en contra, principalmente, de las clases y sectores sociales subalternos y de la naturaleza, en el afán de subsumir las fuentes primordiales de riqueza. La estrategia de acumulación basada en el despojo y la explotación redoblada del trabajo se conjuga con la opresión y dominación. Ejemplos de lo anterior son el desmantelamiento del sistema de subsistencia social, que despoja a los campesinos de 
su principal posesión para introducirla al "mercado de tierras" y a grandes segmentos del proletariado del acceso al trabajo formal de calidad; la política de represión salarial que vulnera el fondo de vida obrera para transferir mayores márgenes de valor hacia el capital; y el achicamiento de la ciudadanía a su mínima expresión al conferirle la potestad de sufragar por una clase política que no representa los intereses populares.

Las violencias emergentes son aquellas prácticas coercitivas o punitivas que ejercen los poderes establecidos o los poderes fácticos en contra de grupos sociales e individuos subalternos a los cuales se criminaliza o estigmatiza por cuestiones ideológicas, culturales, políticas y sociales, incluyendo a grupos vulnerables, como mujeres, jóvenes, indígenas, indigentes y minorías sexuales. Esta vertiente considera también el uso de la fuerza contra sectores críticos que resisten las políticas oficiales, como sindicatos independientes, movimientos sociales y organizaciones rebeldes. Además de la violencia interpersonal arraigada en agrupaciones sociales, comunitarias y familiares que detonan conflictos intrafamiliares, religiosos, comunitarios y políticos, o que afloran por disputas sobre tierras, propiedades o representación política.

México constituye cimero de las violencias sistémicas perpetradas por el capital corporativo y el poder político. A continuación, revisaremos algunas de las expresiones más representativas.

\section{Despojo y explotación extenuante}

La destrucción del sistema de subsistencia social genera una desbordante sobrepoblación que, desde la óptica del capital, no tienen acomodo laboral. Los sujetos despojados tienen que buscar alternativas de subsistencia en la economía informal, la migración o la criminalidad. La exportación de fuerza de trabajo ha sido una de las especialidades de la economía nacional para depurar el excedente poblacional y abrir una fuente de divisas para sostener las cuentas externas y contener la conflictividad social. La superexplotación no se encajona en el Estado-nación, sino que se 
extiende en la economía del figurativo Sur global: los migrantes forzosos, que buscan trabajo allende las fronteras, habitualmente se insertan en ocupaciones precarizadas, segregadas e inseguras.

Puesto que las grandes corporaciones asumen los privilegios del modelo de acumulación, los sectores económicos de base nacional, a la sazón los mayores empleadores, resultan despreciados por las políticas oficiales y son expuestos al poderío de grandes corporaciones como Monsanto, Nestlé o Wal-Mart, por lo que la quiebra es inminente. Según el Instituto Nacional de Estadística Geografía e Informática (INEGI), de los poco más de 4 millones de unidades empresariales, el 99.8\% son micro, pequeñas y medianas empresas (Mipymes), y generan 52\% del producto interno bruto (PIB) y $72 \%$ del empleo. Como la mayoría de las Mipymes depende de la ocupación y remuneración de la población, de las 400 mil que emergen al año, la mitad quiebra en el corto plazo, y sólo $10 \%$ supera un quinquenio, según la Confederación Nacional de Cámaras Industriales (Concamin) (Gascón, Reforma, 6 de febrero de 2012).

Las estrategias del capital en contra del trabajo son múltiples, pero pueden resumirse en la pretensión de socavar partes sustanciales del fondo de vida - salario directo y salario social, que permiten la reproducción social de los trabajadores y sus familias - para transferirlas a las arcas corporativas bajo la figura de una ganancia acrecentada.

En lugar de que la productividad y competitividad se basen, como postula la teoría convencional, en la innovación tecnológica, la formación de cadenas productivas o la convergencia regional, dichas variables emanan de la explotación redoblada del trabajo vivo, mediante la contención o disminución salarial, el incremento de la intensidad laboral y la prolongación de la jornada de trabajo. A pesar de que la oferta de trabajo barato y la precarización laboran están perdiendo vigor como factores de atracción de la inversión extranjera directa (IED) y como pivotes de la estrategia de "competitividad", el gobierno mexicano, fiel a los mandamientos del "Consenso de Washington”, está empecinado en achicar los salarios, sin 
importar - o quizás buscándolo- que el país pronto se convierta en la economía que ofrece los salarios más bajos del mundo.

Durante la vigencia del modelo neoliberal, entre 1982 y 2011, la economía mexicana ha mostrado un desempeño mediocre, pues registra una tasa de crecimiento promedio anual de $2.1 \%$, la peor de América Latina. En ese mismo lapso, el salario mínimo ha mostrado un crecimiento real promedio anual de $-3.8 \%$, por lo que ha registrado una pérdida del poder adquisitivo de 71.3\% (Rodríguez, 2011). Según la información oficial, en México 5.8 millones de trabajadores, $12.7 \%$ de la población económicamente activa (PEA), padece "condiciones críticas": perciben menos de dos salarios mínimos, trabajan más de 48 horas a la semana y carecen de seguridad social o prestaciones (INEGI, 2011).

En México, los tecnócratas desprecian la recuperación salarial como basamento de un desarrollo incluyente y a los trabajadores como un sector social imprescindible para el crecimiento económico, pues se supone que el consumo alienta la inversión y el empleo. Inclusive, suele argumentarse que los costos laborales, los impuestos y la regulación gubernamental impactan desfavorablemente en la productividad, por ello justifican la contención salarial, como una suerte de sacrificio de las presentes generaciones para garantizar la prosperidad de las futuras generaciones. No obstante, la correlación entre salarios y productividad no es clara, pues mientras los salarios se mantiene deprimidos, la productividad muestra una dinámica irrelevante: entre 1994 y 2010 creció sólo 0.4\% (OCDE, 2011).

La mayoría de los trabajadores ocupados percibe salarios insuficientes para cubrir las necesidades familiares básicas. Los trabajadores que no perciben ingresos representan el 8.7\%; los que perciben hasta un salario mínimo, 13.0\%; hasta dos salarios mínimos, 22.7\%; hasta tres salarios mínimos, 21.1\%; entre tres y cinco salarios, $15.9 \%$, y más de cinco salarios mínimos, 8.5\%. Los trabajadores ocupados que perciben tres salarios mínimos o menos representan el 56.8\% (INEGI, 2011). Los trabajadores que perciben un salario de 6 mil pesos o menos destinan más de la 
mitad del ingreso a la compra de alimentos, justo en un contexto de crisis alimentaria atizado por el incremento de los precios de los alimentos de la canasta básica. Otros de los rubros del gasto que erosionan el ingreso familiar, al menos en el ámbito urbano, es el transporte público a los centros escolares y laborales. Las posibilidades de diversificar el consumo se achican drásticamente.

Si bien América Latina constituye el escenario donde perviven los patrones de distribución del ingreso más inequitativos en el orbe, la mayoría de los países de la región implementa políticas de corte posneoliberal, que entre otras medidas contempla la recuperación gradual de los niveles salaries. México, junto con Honduras, encabeza la cifra negra de la pobreza. La Comisión Económica para América Latina y el Caribe (CEPAL) estima que la población pobre aumentó de $34.8 \%$ a 36.3\% (González, El Universal, 30 de noviembre de 2011). La indigencia pasó de $11.2 \%$ a $13.3 \%$, entre 2009 y 2010. Los datos oficiales reportan que la pobreza patrimonial creció 13 millones de pobres entre 2006 y 2010, es decir, pasó de 44.7 millones de personas a 57.7 millones. Entre 2006 y 2010, la pobreza patrimonial aumentó 13 millones. México está considerado entre la veintena de países con la peor distribución del ingreso. En mayo de 2011, México estaba situado en el segundo lugar de los países de la OCDE con la brecha más amplia entre salarios bajos y altos.

\section{Saqueo de recursos naturales}

La otra fuente de riqueza, la naturaleza, es arrasada como un simple insumo productivo que tiene que ser transformado a la mayor velocidad posible. La depredación es redoblada por el despojo de bienes comunes (tierra, agua, aire, bosques, biodiversidad) y bienes nacionales (empresas públicas, infraestructura, servicios públicos), bajo el ardid de que el sector social es improductivo y el sector público es ineficiente y corrupto. El intercambio desigual ambiental es patente: la capacidad de remplazo de la naturaleza no corresponde a la tasa de rendimiento empresarial y la 
capacidad de reproducción social se resquebraja. De un lado, las grandes corporaciones expanden sus fuentes de ganancia, con el apoyo del Estado, y, del otro, los sectores populares y las comunidades pierden autonomía y padecen el quebranto de sus modos de vida y trabajo. De manera enfática, las corporaciones extractivistas toman a México como enclave para sustraer, sin reparos éticos o ambientales, cantidades inconmensurables de materias primas (minerales, acuíferos, maderas, petróleo). La práctica indiscriminada de minaría a cielo abierto es un ejemplo perverso de la voracidad capitalista.

Desde la década de los ochenta, los organismos financieros internacionales promueven la entrada del capital multinacional en yacimientos energéticos (petróleo y gas) y reservas minerales (metales y tierras raras). En consecuencia, los gobiernos neoliberales imponen contrarreformas a favor del extractivismo, a fin de que el país figure como un espacio atractivo para la inversión y fuente de ganancia extraordinaria de corto plazo. Lo cual embona con la mayor demanda de minerales, el aumento del precio del oro desde mediados de los noventa y la efervescencia de una nueva "fiebre del oro", es decir, la ubicación de un nicho alternativo para la especulación, ante el estallido de las burbujas financieras. La explotación a cielo abierto ha proliferado en las últimas dos décadas como respuesta a las crisis financieras, principalmente de Europa y Estados Unidos, pues los metales preciosos representan un "refugio" para la inversiones que buscan ganancia extraordinaria.

Ante la disminución de reservas con alta concentración de minerales, las corporaciones mineras desarrollan grandes proyectos de explotación de tajos a cielo abierto mediante el uso de nuevas tecnología que permiten la recuperación de minerales metálicos (oro, plata y cobre, principalmente) que se encuentran dispersos en amplias extensiones territoriales. En México, 293 corporaciones mineras extranjeras ( $75 \%$ canadienses) cuentan con 808 proyectos, 506 de ellos de oro y plata (Ramírez, 2012). La mayoría están en etapa de exploración, pero más de 70 están produciendo y al menos 25 operan bajo el esquema de megaminería a cielo 
abierto y lixiviación con cianuro para recuperar oro y plata. De mantenerse el frenético ritmo de explotación —es posible extraer tres metros cúbicos de oro en una década de vida útil de una mina a cielo abierto (Ruiz, La Jornada, 21 de julio de 2012)-, en el curso de una década cerca del 30\% del territorio nacional podría estar destruido, una superficie equivalente al territorio concesionado a la minería, sobre todo metálica.

El resurgimiento de la gran minería impulsado por la política gubernamental concita un intercambio desigual que permite la apropiación de la renta de la tierra bajo la forma de una ganancia extraordinaria en el corto plazo, la transferencia de reservas minerales no renovables hacia el extranjero, principalmente, a cambio de mínimos beneficios tributarios, un deterioro ambiental irreparable, la explotación laboral extenuante y el despojo de bienes comunes. En el plano local, el extractivismo catapultado por la megaminería multiplica los costos sociales y ambientales: contaminación de aguas, destrucción del territorio, liberación de metales pesados, pérdida de biodiversidad, deterioro de recursos culturales, desplazamiento de comunidades; además de que propicia la corrupción y violación de leyes (Sacher, 2010). Los casos de la Minera San Xavier en el Cerro de San Pedro en San Luis Potosí; Goldcorp en el complejo Peñasquito en Mazapil, Zacatecas; Toronto Alamos Gold en la mina Mulatos, en Sonora, Compañía Minera Gammon Lake en Ocampo, Chihuahua son fieles testimonios de cómo la corporaciones transfieren los costos socioambientales a la población. La tentativa de desarrollo local incluida en los discursos justificatorios es desmentida, una y otra vez, por la realidad.

\section{Especulación y capital ficticio}

Como sucede en gran parte de los países subdesarrollados, el predominio del capital financiero repercute en la pérdida de soberanía financiera. Los organismos financieros internacionales (Banco Mundial, Fondo Monetario Internacional y Banco Interamericano de Desarrollo) imponen los programas de ajuste 
estructural como condición para otorgar préstamos. Las condiciones leoninas inmersas en las cartas de intención, además de trastocar la autonomía e independencia económicas, compromete buena parte del excedente social para pagar la duda externa, en detrimento del financiamiento al gasto público. El capítulo de la deuda externa en México da cuenta de la sangría de recursos hacia el exterior. Según el Banco de México y la Secretaría de Hacienda y Crédito Público, la deuda externa bruta total asciende a $257 \mathrm{mil}$ millones de dólares en 2011, impulsada por la inversión extranjera en bonos gubernamentales y la contratación de deuda para financiar obras de infraestructura energética (Zúñiga, La Jornada, 10 de junio de 2011). Según la información oficial, el gobierno paga anualmente una cantidad de 5 mil 400 millones de dólares al pago de deuda (Zúñiga, La Jornada, 9 de mayo de 2012).

El capital ficticio, movilizado por los grandes bancos de inversión, bancos privados internacionales, fondos de pensiones y fondos de inversión, recurre a la especulación desenfrenada en pos de altas ganancias de corto plazo. Al efecto, controla las operaciones bursátiles, bancarias y crediticias, por lo que los embates de las burbujas financieras generar sobresaltos y turbulencias permanentes en el derrotero económico nacional.

El sistema financiero mexicano no existe como tal. La banca de desarrollo, cuyos resabios deambulan en las siglas de Nacional Financiera (Nafin), Banco de Comercio Exterior (Bancomext) y Banco de Crédito Rural (Banrural), es prácticamente inexistente, y en lugar de canalizar recursos crediticios para el desarrollo estratégico de sectores económicos y regiones, financia capital de riesgo de grandes corporaciones e incurre en prácticas de financiarización. La banca comercial está prácticamente extranjerizada y los mercados de valores, dinero y divisas también son controlados por agentes especuladores externos. La banca del sector social y popular atraviesa por una fuerte crisis profunda que deteriora la capacidad productiva de las microempresas y productores rurales, en tanto que las prácticas crediticias son restrictivas y onerosas. En el colmo, los fondos de pensiones son canalizados a la 
especulación o financiamiento de grandes proyectos de inversión privados, por lo que en lugar de afianzar la vejez de los trabajadores retirados y garantizar el futuro de los trabajadores activos, se inculca una perniciosa cultura que canaliza estos recursos solidarios a la economía de casino. Asimismo, de manera creciente, los recursos presupuestales de todos los niveles de gobiernos se canalizan, también, a operaciones bursátiles y otros canales de la inversión especulativa, o hacia esquemas de inversión controlados por las figuras de coinversión público-privados, como los proyectos para prestación de servicios (PPS), que de manera encubierta, representa una onerosa transferencia de recursos públicos a las arcas privadas de corporativos vinculados políticamente con los gobernantes. Las actividades ilícitas, como el lavado de dinero, articulan un conglomerado de actividades económicas de los sectores y ramas industriales, inmobiliarias, financieras, turísticas y comerciales, algunos vinculados al crimen organizado, como el narcotráfico, el tráfico de armas y la extorsión, y otros derivados de las prácticas corruptas de los sectores público y empresarial (Reveles, 2010). Y los embates especulativos contra la moneda aunado a la recurrente fuga de capitales, la remisión de ganancias al extranjero y el oneroso pago por varios conceptos de deuda, representan una transferencia y fuga sistemática de excedente económico que vulnera la capacidad de acumulación nacional y abona a la expansión de las desigualdades sociales.

Los rescates bancarios representan una escandalosa y socorrida fuente de riqueza, corrupción y complicidad entre la clase política y la empresarial. Un caso sintomático es el Fondo Bancario de Protección al Ahorro (Fobaproa) que representó el pago a los banqueros quebrados, para resarcir sus fortunas y apuntalarlos en el mundillo de los multimillonarios, con cargo al erario, bajo el ardid de que se estaba rescatando a los ahorradores. En lugar de que los accionistas y propietarios asumieran las pérdidas, el gobierno resolvió el problema como si se tratase de deuda pública, incluso sin hacer distinciones entre créditos vencidos y fraudes financieros. Es el clásico mecanismo que ha sido conocido como 
"socializar la pérdidas y privatizar las ganancias". Algunos de los beneficiarios del salvataje están en las listas de multimillonarios de la revista Forbes y la mayor parte conforma el núcleo empresarial que da vida al "capitalismo de los compadres".

Petróleos Mexicanos (Pemex) genera una renta petrolera que representa una fabulosa fuente de recursos que no se canaliza de manera estratégica para financiar el desarrollo nacional. Gran parte de esos recursos se dilapida en los lodos de la corrupción sindical y gubernamental, se transfiere a empresas privadas que se beneficias de los llamados contratos incentivados, se destinan a cubrir diversos rubros del gasto corriente y también se canalizan a la inversión financiera de alto riesgo. Pemex es una empresa altamente rentable que está sujeta, sin embargo, a un régimen impositivo contraproducente, pues termina por estrangular su operación.

La transferencia de ganancias al exterior es recurrente. Un caso sintomático es el de Bancomer, que remite dividendos a la matriz española BBVA, hasta en un margen de $70 \%$. La sospecha de lavado de dinero del crimen organizado envuelve a la banca comercial y casas de cambio. Al respecto, se ha denunciado puntualmente a HSBC y a bancos estadounidenses.

El sistema hacendario mexicano se caracteriza por ser altamente regresivo. La incapacidad recaudatoria inducida por el modelo neoliberal y la errática estrategia redistributiva repercuten en un impresionante rezago social y regional. De acuerdo con la Organización para la Cooperación y el Desarrollo Económicos (OCDE, 2011), entre 2001 y 2010, México alcanzó una recaudación promedio anual equivalente a $18 \%$ del PIB, en tanto que los países desarrollados alcanzaron el 35\% en ese periodo. La hacienda pública configura un paraíso fiscal que beneficia permanentemente a las grandes corporaciones nacionales y multinacionales. La evasión y exención de impuestos resulta prácticas socorridas, amén de que muchas inversiones especulativas y fraudulentas están prácticamente exentas.

Las grandes corporaciones de base nacional, como Cemex, Vitro, Gruma y Femsa, canalizan importantes sumas de ganancias a 
la inversión en instrumentos financieros especulativos, y descuidan la inversión productiva (Mendoza, 2010). En lugar de jugar el papel de locomotoras del mercado interno, estas corporaciones recurren a los mercados especulativos con la expectativa de agenciarse ganancias de corto plazo.

\section{Dominación sin consenso}

Al imponerse el neoliberalismo, el pacto nacionalista-populista que ofrecía una mínima red de protección al proletariado, campesinado y clase media - fue reemplazado por el neocorporativismo, es decir, la coalición de intereses del gran capital y el Estado. Este nuevo pacto desencadena una agresiva ofensiva en contra de los trabajadores y reinserta la economía mexicana a las redes globales de capital bajo la premisa de que el país es un manantial de trabajo barato, flexible y desorganizado. El corporativismo se entendía como el triunvirato del Estado, el capital y el trabajo. Un pacto multiclasista articulado por el presidencialismo priísta que regulaba el sistema político y las relaciones obrero-patronales, con ciertos márgenes de beneficio social y evidentes privilegios para los líderes cooptados. El neocorporativismo excreta al sector obrero para conceder todos los privilegios al sector empresarial. Los liderazgos corruptos mantienen bajo control a la masa obrera. Un ejemplo notable es el Sindicato Nacional de Trabajadores de la Educación (SNTE), que funge como una maquinaria electoral al servicio de los partidos dominantes. En tanto que los sindicatos blancos o de protección negocian los contratos laborales según las exigencias empresariales.

Pese a la "transición a la democracia" verificada en 2000, luego de que culminara la prolongada hegemonía del partido de Estado, el PRI, en México prevalece un régimen político donde se manda sin obedecer, es decir, se ejerce la dominación sin consenso. El ritual democrático se reduce al acto en el cual el electorado convalida, en cada comicio, al sistema de poder. El rejuego electoral permite, a lo sumo, la depuración y reciclaje de la clase política, 
pero tiene tras bambalinas la preeminencia de pactos económicopolíticos que consolidan las estructuras de acumulación y poder. La democracia de élites es operada por el sistema de partidos, la partidocracia, que se ha decantado hacia la derecha y ha consecuentado el pragmatismo, utilitarismo, conservadurismo y oportunismo. En contraste, la ciudadanía representa, para ese sistema, una masa de votantes que tiene el privilegio de expresarse votando: es una ciudadanía mínima.

La derechización entraña la idea de que la política, o la pospolítica, no sirve más para reivindicar luchas clasistas empeñadas en transformar la sociedad, sino que es un campo reservado para expertos, consultores, tecnócratas y administradores, que "saben como hacer las cosas", y los gobernantes, a lo sumo, "rinden cuentas" al electorado (Žižek, 2009). El ejercicio del poder termina por fetichizarse: los gobernantes exalta la imagen personal, toman decisiones sin consultar, emplean discrecionalmente los recursos públicos y prohíjan una camada de nuevos ricos. En consonancia con la exigencia corporativa, mantienen a raya la baratura del trabajo, contienen las movilizaciones sociales, criminalizan a los pobres, estigmatizan a los jóvenes y vilipendian a los críticos. Bajo el reduccionismo liberal, el Estado se constriñe a las funciones de seguridad, ley y orden, a la vez que promueve la transferencia de activos, recursos y servicios a la codiciosa órbita privada.

\section{INSEGURIDAD HUMANA: \\ VERTEDERO DE VIOLENCIAS SISTÉMICAS Y DEGRADACIÓN SOCIAL}

\section{Pérdida de soberanía alimentaria}

La figuración de que al amparo del orden alimentario dirigido por las agroindustrias multinacionales cualquier persona puede acceder a alimentos inocuos y nutritivos para alcanzar una vida sana y activa termina por ser derrocada. Se estima que 800 millones de personas en el mundo no pueden consumir suficientes calorías para cubrir sus necesidades vitales y que, al contrario, millones 
de personas consumen alimentos con suficiente o excesivo aporte calórico, pero baja calidad nutricional. En México, 18.8\% de la población está imposibilitado para adquirir la canasta básica y sólo $55 \%$ de los hogares disponen de seguridad alimentaria.

La inseguridad alimentaria golpea, sobre todo, a la población pobre que padece desempleo, informalidad laboral y exclusión de programas asistenciales, y que resiente, por tanto, el continuo incremento del precio de alimentos y los embates de las crisis recurrentes. La paradoja de la malnutrición afecta igualmente a quienes padecen inseguridad alimentaria y quienes sufren de obesidad.

En el trasfondo, la inseguridad alimentaria proviene del desmantelamiento del sistema de subsistencia social, cuando la economía campesina es abandonada por el Estado y el campo reorientado abruptamente hacia la exportación y la entrada de la agroindustria multinacional. El consecuente deterioro de la producción nacional de alimentos, el desmantelamiento de la autosuficiencia alimentaria y la bancarrota del campo repercutió en la caída en los niveles de ingresos y calidad de vida del sector social de la economía. A la quiebra rural le deviene la emigración, sobre todo de jóvenes, a Estados Unidos y las grandes ciudades del país.

El desmantelamiento productivo y el deterioro de la infraestructura natural es alarmante. Cerca del $75 \%$ de las tierras cultivables en México está en proceso de desertificación y su rehabilitación tardaría más de cinco siglos. La tecnificación del campo ha fracasado. Se importa $42 \%$ de los alimentos para consumo humano. A finales de 2012 se estima que la dependencia alimentaria alcanzará $60 \%$ debido a la exacerbada importación de productos alimentarios. México perderá definitivamente su soberanía alimentaria, pues sólo es autosuficiente en la producción de huevo, pero en casi todos los demás alimentos de alta demanda recurre a las importaciones: $67.9 \%$ del arroz; $42.8 \%$ del trigo, 31.9\% del maíz y $8.2 \%$ del frijol. La importación de ganadera también es significativa: $40 \%$ de la leche, $53 \%$ de carne de aves, $68 \%$ de carne de res y $78 \%$ de carne de cerdo (Cruz, La Crónica, 19 de enero de 2012). 


\section{Desmantelamiento de la soberanía laboral}

Una de las principales fuentes de riqueza, además de la naturaleza, es el trabajo vivo. La economía basada en la explotación laboral necesita garantizar condiciones mínimas de vida y seguridad para los trabajadores, amén de propiciar expectativas de desarrollo. Empero, el capitalismo neoliberal está volcado a la sustracción de ganancia inconmensurables a costa de la calidad de vida de trabajadores y desposeídos. La gestión corporativa precariza el ámbito laboral y degrada la condición humana para maximizar las ganancias, y lo hace con mayor crudeza en periodos de crisis, como los acontecidos en los últimos años.

En un contexto macroeconómico donde las estrategias de acumulación por despojo y las políticas monetaria y fiscal constriñen el mercado interno, el mercado laboral se distingue por su carácter excluyente y estrecho. La economía mexicana adquiere la incapacidad crónica de crecer sostenidamente, sólo lo hace a una tasa promedio anual de $2.1 \%$, y, en consecuencia, asume la incapacidad estructural de generar las fuentes de empleo formal de calidad que demanda la población en edad de trabajar, por lo que el síntoma evidente es la pérdida de soberanía laboral (Márquez, 2008). En 2011 la PEA sumaba 49.5 millones de personas, de las cuales sólo 5.5\% estaban desocupadas (INEGI, 2011); no obstante, la desocupación podría alcanzar el $25 \%$ si se toman en cuenta a quienes no perciben ingresos y quienes son excluidos del trabajo estando disponibles; más aún, la proporción sería mayor si se contabilizan a los migrantes, excluidos económicos por antonomasia, que al menos en el último sexenio sumaron 2.5 millones de personas.

El régimen de inseguridad laboral promueve la informalidad como columna vertebral del mercado laboral. El crecimiento del empleo informal es superior al formal: según el Instituto Mexicano de Seguridad Social (IMSS), en el último trimestre de 2011 los empleos informales crecieron $13.4 \%$ por sólo $3.4 \%$ de los formales (Fernández, La Jornada, 29 de marzo de 2012). 
Disponer de una fuente de trabajo asalariado no es garantía de una vida digna. El signo de la precarización laboral cubre a la mayoría de trabajadores: cerca de 14 millones sobrevive en la informalidad; 30.1 millones de trabajadores no tienen acceso a la salud; más de 6 millones obtienen hasta un salario mínimo; más de 10.6 millones ganan entre uno y dos salarios mínimos, y casi 10 millones entre dos y tres minisalarios. La precariedad laboral absorbe a $63 \%$ de la población ocupada. Aunque el nivel de precarización puede ser mayor al considerar la duración de las jornadas de trabajo, pues 12.9 millones laboran más de 48 horas semanales (INEGI, 2011).

La contención salarial y el empleo precario, son dos de los puntales para abaratar costos corporativos y edificar la "competitividad" de la economía mexicana.

\section{Desigualdad y exclusión educativa}

En el ámbito internacional, México ocupa el lugar 55 en materia de acceso a la educación. Los rasgos de exclusión educativa salen a la luz: más de 34 millones de personas sufren rezago educativo, analfabetismo o tienen apenas cuatro años de estudio; 1.4 millones de niños mexicanos no asisten a la escuela; $40 \%$ de la población tiene nivel uno de lectura; ocho de cada diez indígenas no cuentan con educación básica; existen 7 millones de analfabetas; 1 millón 324 mil mexicanos tienen menos de cuatro años de estudio, y las mujeres indígenas que solamente hablan su lengua, tienen $15 \%$ más probabilidades de ser analfabetas (UNESCO, 2010).

El sistema educativo mexicano reproduce las desigualdades sociales: el sistema educativo no brinda acceso a una gran cantidad de niños y jóvenes, principalmente pobres. A mayor edad, disminuye el porcentaje de asistencia: entre 4 y 5 años, la asistencia es de $88.6 \%$ y entre 15 y 17 es de $65 \%$, y entre más pobreza, menor asistencia, por ejemplo, entre 16 y 17 años, los "no pobres" asisten 72\% y los pobres sólo el 55\% (Muñoz y Silva, 2012). De igual modo, los alumnos pobres presentan la mayor 
incidencia de rezago, por reprobación, por ingreso tardío al ciclo escolar, lo que los coloca en el umbral de la deserción. Los logros educativos más bajos se registran en escuelas públicas de colonias, barrios o localidades con mayor pobreza. Lo cual repercute el aprovechamiento de los contenidos en materias básicas, como matemáticas y español.

Como en otros capítulos de la vida social, el Estado neoliberal prohíja una colosal deuda en materia educativa que desconoce la obligatoriedad constitucional de garantizar la educación primaria: 15.4 millones de mexicanos mayores de 15 años no han concluido ese grado escolar (cifra que supera $13.7 \%$ a la matrícula del actual ciclo escolar de la primaria pública); 16.9 millones de mexicanos del mismo grupo de edad tienen la secundaria inconclusa (tres veces más de la matrícula de ese segmento educativo) (Ulloa, 2012). Mientras que el grueso del gasto federal educativo se canaliza a la educación básica (61\%), en un contexto donde la deuda social se profundiza, la educación superior percibe recursos comparativamente más limitados (16\%). El carácter excluyente del sistema educativo mexicano se ilustra por la trayectoria de embudo, amplio en la entrada y estrecho en la salida: la cobertura educativa en el nivel básico es de $99 \%$; en el nivel medio superior de $61 \%$, y en el nivel superior de $29 \%$.

Asimismo, el gobierno federal incumple el mandato de destinar un presupuesto público equivalente al 1\% del PIB a los rubros de educación, ciencia y tecnología, pues apenas invierte $0.6 \%$ en educación y $0.3 \%$ en ciencia y tecnología. En contraste, en los países "desarrollados", ya desde hace dos décadas, la inversión en ambos rubros supera el 1\% (Ramírez, 2012).

Para muchos analistas, la palanca del desarrollo está cifrada en la ciencia y la tecnología. Sin embargo, a formación de investigadores, científicos y tecnólogos es muy limitada: sólo el 6.9\% de la matricula escolarizada del país cursa alguna especialidad, maestría o doctorado. De ellos, sólo el 10\% está cursando un doctorado. En México sólo se están graduando un poco más de 2 mil doctores al año, mientras que en Brasil o Corea del Sur, lo hacen 
alrededor de 10 mil. Lo cual se traduce en una baja producción científica que se puede medir por publicaciones académicas o patentes, y en parte explica la dependencia tecnológica y la baja capacidad de inventiva.

\section{Exclusión y criminalización de las juventudes}

En México existen 36.2 millones de personas entre 12 y 29 años de edad, no obstante, 8 millones (22\%) ni estudian ni trabajan; se estima que al concluir 2012 esta cifra podría ser de 9 millones. Según el Banco de México, entre 2007 y 2011 la PEA fue de 1 millón 300 mil personas en promedio anual, en dicho periodo los jóvenes demandantes de empleo aumentaron en 6.5 millones, pero sólo se generaron 2 millones 972 mil puestos. Los jóvenes son los más golpeados por el desempleo, pues 66\% labora en la informalidad, adicionalmente, $40 \%$ trabajan en empresas que no ofrecen seguridad social, ni prestaciones (OCDE, 2011).

El Estado neoliberal financia insuficientemente al sistema de educación pública y canaliza recursos públicos al sector privado en una estrategia tendiente a mercantilizar la educación. La juventud mexicana padece el rechazo sistemático del sistema educativo nacional, en contraposición a otras naciones latinoamericanas, donde la política pública está orientada a cubrir la demanda. Por ejemplo, en 2012, se registraron más de 122 mil jóvenes para ingresar alguna licenciatura de la UNAM, pero sólo fueron aceptados 11 mil 116, en tanto que el IPN rechazó a 66 mil aspirantes y sólo aceptó a 24 mil 200 jóvenes.

Pero quienes egresan del nivel superior no tienen ninguna garantía de insertarse favorablemente en el mercado laboral. Entre 2001 y 2008, egresó un promedio anual de 305 mil estudiantes de las instituciones de educación superior, es decir, salieron a la luz 2.7 millones de nuevos profesionistas en ese lapso, pero la economía mexicana sólo pudo generar 1.8 millones de empleos permanentes, lo que ilustra la baja capacidad de absorción de nuevos profesionistas, sin considerar el rezago acumulado. Frente al mito 
de que ahora disponemos de jóvenes con la mejor preparación educativa de la historia, el modelo neoliberal erige un muro infranqueable. La tasa de generación de egresados universitarios es de $5.6 \%$, pero la economía crece a sólo $2.2 \%$, por lo que la generación de empleos permanentes muestra una dinámica raquítica de apenas $1.1 \%$. Los jóvenes profesionistas, aquellos privilegiados que lograron salir del embudo educativo, no disponen de un mercado laboral formal de calidad que los acoja y los proyecte hacia un futuro promisorio.

\section{Ciudadanía mínima}

La ciudadanía es considerada como un sujeto mínimo que sólo es convocada a sufragar por personajes reciclados de la clase política que detentan el monopolio de la representación. Tras un incesante bombardeo propagandístico, el sistema político pretende persuadir a esta ciudadanía con la idea de que la expectativa del cambio sólo anida en las urnas. El adormecido debate político centellea fraseos demagógicos y consignas prefabricadas por ejércitos de asesores. El esmirriado menú presidencial oferta presuntos representantes populares que poco se atreven a anunciar la estrategia de desarrollo nacional.

La colonización de la conciencia colectiva es un logro inapreciable de los grandes medios de comunicación, destacadamente la televisión, que inoculan en sus audiencias ideas adocenadas de la política y anestesian el pensamiento con programación mediocre. El objetivo es despolitizar a la población, que permanece desinformada y renuncia a la potestad del mandato.

El sistema de propiedad de los medios de comunicación en México destaca por ser uno de los más concentrados y privatizados del mundo. En la televisión prevalece un duopolio (Televisa/TV Azteca) que domina más del 90\% de la televisión abierta, y un monopolio (Telmex) en telefonía y tecnologías de la información. Televisa posee el $65 \%$ de las frecuencias de televisión abierta, con 225 estaciones repetidoras de sus cadenas 
nacionales, acapara $68 \%$ de las audiencias y concentra $70 \%$ de la publicidad en medios electrónicos y $58 \%$ de la publicidad en todos los medios (Villamil, 2009).

Un país no puede llamarse democrático, así se constriña a la sola esfera electoral, como es el caso, cuando carece de medios de información confiables y honestos. En México prevalece un modelo comunicacional antidemocrático, domeñado por las corporaciones televisivas, cuyo poder de penetración en las audiencias les permite modelar y mercantilizar la conciencia colectiva de amplios sectores de la población. Para la mayoría de la población -entre 70 y $80 \%$, dependiendo de la encuesta- la televisión representa la principal fuente de información y entretenimiento.

\section{VÁLVULAS DE ESCAPE DE LOS EXCLUIDOS}

\section{Informalidad}

Frente a la incapacidad estructural de la economía mexicana para generar los empleos formales que demanda la población, los trabajadores buscan una fuente de ingreso en la llamada economía informal. Las fuentes oficiales reportan que 14 millones de personas están inmersas en ese sector. En los últimos once años, el trabajo informal aumentó $41.12 \%$ y el empleo formal $15.7 \%$, es decir, un trabajo formal por tres informales. No obstante, estudios independientes consideran que la presencia de la informalidad es mucho mayor. Uno de ellos considera que, para el cuarto trimestre de 2011, 28 millones trabajaban en condiciones precarias, por lo que $60 \%$ de los trabajadores está en la informalidad, sin seguridad social ni prestaciones laborales, incluyendo empresas e instituciones gubernamentales (Cruz, 2012). La diferencia estriba en que el estudio considera a grupos de trabajadores subordinados, es decir, asalariados o con percepciones no salariales, sin acceso a los servicios de salud y seguridad social, pero que laboran en empresas o instituciones formales. 
La mayor parte del trabajo informal se concentra en los servicios (57.4\%). Entre los trabajadores informales, 90\% sólo cursó algunos años de nivel básico. El IMSS reportan a 15.4 millones de personas con empleo formal en México, sin embargo se estima que existen 50 millones en edad de formar la PEA.

En el último quinquenio sólo se generaron 939 mil 560 empleos permanentes y 417 mil 62 empleos eventuales: un millón 356 mil 622 plazas, contra una demanda de 5.2 millones, por lo que uno de cada cuatro ingresaron al mercado laboral formal (Fernández, La Jornada, 9 de febrero de 2012).

\section{Migración forzada}

La migración compulsiva de mexicanos hacia Estados Unidos encuentra su explicación más profunda en la estrategia de acumulación por despojo cuyo propósito es desmantelar el modo de vida y trabajo del sector social, rural y urbano, para ensanchar los ámbitos de valorización de las grandes corporaciones. Una pléyade de campesinos, obreros, profesionistas, empleados, estudiantes y demás sectores pierden, de la noche a la mañana, el acceso a medios de producción y subsistencia, y se ven obligados a buscar un trabajo remunerado allende las fronteras, donde existe una demanda copiosa por trabajo barato, en distintas ramas de la economía.

La migración indocumentados de origen mexicano pasó de 2 millones en 1990 (46.5\% del total) a 6.5 millones en 2010 (58\% del total). Ningún otro país del mundo cuenta con una magnitud tan grande de población en el extranjero en condición irregular y, por tanto, sometida a condiciones de vulnerabilidad, discriminación y exclusión social (Passel y D’Vera, 2010). Durante la vigencia del TLCAN, los migrantes mexicanos han cubierto una parte importante de la demanda laboral estadounidense. De los $18.1 \mathrm{mi}$ llones de nuevos puestos de trabajo generados en Estados Unidos entre 1994 y 2011, casi una quinta parte (18.3\%) estuvo ocupada por trabajadores nacidos en México. Poco más de la mitad de la 
demanda en el período, es decir, 55.8\%, fue cubierta por trabajadores inmigrantes, de los cuales la tercera parte (3.3 millones) fueron originarios del país. La ocupación de migrantes mexicanos creció 99\% frente a un crecimiento de $15.1 \%$ del empleo total en Estados Unidos, en el periodo de referencia.

Sin embargo, los migrantes mexicanos ocupados carecen de una amplia gama de servicios sociales: la gran mayoría no tiene acceso a la seguridad social ni a programas de asistencia pública. El grueso de los migrantes mexicanos asalariados ocupa el escalón más bajo en la percepción de ingresos y presenta los mayores índices de pobreza. En 2011, 3.5 millones de migrantes mexicanos residentes en Estados Unidos se ubicaron en la categoría de pobres, entre los mexicanos ocupados 1.4 se encontraron en esa situación, su descendencia observa proporciones similares de pobres, $28 \%$ de los 20 millones de nativos de ascendencia mexicana (6.2 millones). El acceso a los servicios de salud tiende a ser asimismo limitado: más de 2 de cada 10 migrantes mexicanos ocupados no tiene acceso al seguro de salud, casi ocho de cada diez carece de un plan de pensión y siete de cada diez no tiene un seguro ofrecido por el empleador. Los niveles educativos de los mexicanos siguen siendo relativamente bajos, frente a otros grupos nacionales y ante la población de origen mexicano nacida en Estados Unidos: 6 de cada 10 cuentan con menos de 12 años de escolaridad.

\section{Criminalidad}

Como remache del modelo depredador, irrumpe la violencia armada que desgarra el tejido social e impone la percepción del miedo colectivo. El gobierno panista, que emerge de un cuestionado proceso electoral rayano en el fraude, emprende una "guerra contra el narcotráfico" que militariza la vida cotidiana y, subrepticiamente, coacciona a la población a fin de preservar el régimen político, que atraviesa la peor crisis de legitimidad de la historia reciente. 
Entre 2007 y 2011, el presupuesto para el aparato de seguridad se incrementó 75\%, pero la comisión de homicidios creció $65 \%$. El modelo policiaco-militar desencadena una espiral de violencia que contabiliza más de 70 mil muertos, 18 mil desaparecidos y 120 mil desplazados, amén de familias desgarradas, mujeres abandonadas, hijos desamparados y localidades amedrentadas. En ese contexto, los migrantes en tránsito procedentes de Centroamérica son presa fácil de asesinato, explotación, robo, secuestro, extorsión y violación.

El tobogán de la violencia trastoca el tejido social y sega la vida de sectores, como las mujeres, sobreexpuestas como grupo vulnerable. Paradójicamente, la propagación del miedo genera un reclamo ciudadano de mano dura, de modo que el modelo policial asciende en una espiral esquizofrénica: la oferta genera su propia demanda.

\section{MOVIMIENTOS SOCIALES}

Los movimientos sociales que pretenden cambiar las estructuras de poder siempre corren el riesgo de desactivarse ante la cooptación o coerción estatal. Algunas organizaciones dejan un legado social, como el Ejército Zapatista de Liberación Nacional (EZLN) que recupera la noción de democracia como "mandar obedeciendo", recrea el pensamiento crítico e implementa prácticas autogestivas. Los movimientos de resistencia responden a problemas inmediatos, no necesariamente orientados por un proyecto de cambio. Los movimientos rurales más representativos de la acumulación por despojo son del ámbito rural: El Barzón y el Campo no Aguanta Más. El embate contra los trabajadores ha propiciado la resistencia del Sindicato Mexicano de Electricistas y de los sindicatos de Mexicana de Aviación, mineros y el magisterio. La "guerra contra el narcotráfico" ha generado un gran caudal de víctimas y detonado la aparición del Movimiento por la Paz y con Justicia y Dignidad, que ha recorrido el país en una cruzada de concientización, pero también se ha sentado a negociar con el gobierno, sin grandes resultados. 


\section{CONCLUSIÓN}

El proceso de neoliberalización impuesto en México ha derivado en una escalada de descomposición económica, involución política y degradación social que dibuja una colosal crisis, no del modelo neoliberal, que ha cumplido con creces su objetivos de concentrar capital, poder y riqueza entre los sectores oligarcas y los grandes interesas multinacionales, sino que entraña una fractura en el ciclo de reproducción social y en el metabolismo que articula a la sociedad con el medio natural. Las estrategias de acumulación y dominación consecuentan prácticas violentas bajo la figura del despojo, explotación y dominación que se ejercen no como requerimientos ciegos del sistema en pos de la maximización de la ganancia, sino también como la pretensión de vulnerar las capacidades vitales, intelectuales y transformadoras de los sectores, clases y grupos sociales subalternos, que son considerados por la ideología y cultura dominantes como recursos humanos abundantes y desechables, con derechos mínimos.

Conferir un fundamento humano al desarrollo escapa a los propósitos políticos e institucionales del capitalismo neoliberal, a no ser que se trate de medicamentos placebos como la llamada "guerra contra la pobreza" o las buenas intenciones enmarcadas en los objetivos de desarrollo del milenio. El desarrollo humano es resueltamente imposible si no se implementan cambios estructurales, políticos e institucionales en las relaciones de acumulación y de poder, donde la mayor parte de la población es concebida como mercancía humana o fuerza de trabajo barata y desechable. Si la reproducción de la vida humana en un entorno social y natural ordenado por preceptos como la democracia, equidad y justicia es lo que se busca, entonces es indispensable impulsar un cambio a fondo en las pautas del modelo de "desarrollo" neoliberal. Un desarrollo alternativo no sólo resulta posible, sino urgentemente necesario. En principio, es menester afrontar los rasgos más degradantes del proceso de neoliberalización que atosigan a la nación en 
las últimas tres décadas (extractivismo, sobreexplotación, financiarización, criminalización, antidemocracia y dependencia), en tal caso, tiene que ser posneoliberal y replantear la noción misma de desarrollo retomando los principios del verdadero desarrollo humano sustentado en la democracia (representativa, participativa y social), la equidad y la justicia social.

Hay alternativas basadas en el trabajo digno, un neoextractivismo progresista, la soberanía financiera, el desarrollo regional y la seguridad humana. En ese camino, los niños y jóvenes, especialmente los pobres, deben de ser incluidos en las dinámicas del desarrollo. Por ello, es imprescindible promover un cambio cultural donde la ciencia, la tecnología y la educación estén volcados, no a la formación selectiva de "capital humano" abocado a la maximización de ganancia, como ahora ocurre, sino al objetivo de garantizar con dignidad la producción y reproducción de la vida humana en un ámbito natural sano.

El desarrollo alternativo no sólo es un problema económico abocado a la canalización de recursos públicos y privados para organizar la generación de excedente económico y promover mecanismos de distribución acordes a una cierta intencionalidad equitativa y justiciera, sino que también es un proceso político igual o más complejo que reclama la participación social en la toma de decisiones mediante la activación de procedimientos democráticos representativos y participativos que abroguen la vigente dictadura del gran capital que es meticulosamente simulada por una multiplicidad de mecanismos de persuasión, alienación, cooptación y coerción. El gran desafío es incluir a los sectores subalternos, ahora reconocidos simplemente como fuerza laboral desorganizada, precarizada, flexible y despolitizada, que con tal de acceder a una fuente remunerada, está obligada a aceptar condiciones degradantes de trabajo. Construir ciudadanía para el desarrollo humano alternativo es uno de los grandes desafíos, porque se requiere una ciudadanía libre, concientizada y politizada, justamente los que no quiere el actual sistema de acumulación y poder. 
En esa inteligencia, el desarrollo alternativo reclama un cambio cultural a fondo. Se necesita el concurso de todas las clases y sectores sociales, o al menos de la mayoría de la población, a fin de construir un poder social o un poder popular que soporte e impulse un tal desarrollo alternativo. La vía electoral y extraparlamentaria se conjugan en este propósito. Sin embargo, el sistema político cancela las posibilidades de que la sociedad organizada eleve una alternativa de tal calado. Está claro que sin un agente colectivo abocado a la transformación social será imposible impulsar un desarrollo alternativo. El actual sistema de partidos es incapaz de organizar al grueso de la sociedad civil excluida para promover el cambio verdadero, también se muestra desinteresado para fungir como "intelectual colectivo", es decir, la instancia que pone a la palestra los problemas nodales y sus posibles soluciones, pues están inmersos en el juego del poder: la repartición de las parcelas de poder mediante relaciones de complicidad, corrupción y contubernio. El poder popular, autónomo e independiente, consciente y crítico, no surge por generación espontánea ni por iniciativa de los poderes establecidos, sino por la eventual auto-organización de los sectores subalternos: campesinos, obreros, informales, intelectuales, políticos y demás sectores afines.

Aunado a la construcción de un poder social resulta imprescindible formar nuevas generaciones de ciudadanos libres, conscientes, críticos y participativos para impulsar un desarrollo humano de nuevo tipo, es decir, no sólo de un desarrollo montado en la institucionalidad capitalista neoliberal que pretenda otorgar ciertas "oportunidades", “capacidades” y "competencias" a los sectores poblacionales excluidos o marginados para que eventualmente se conviertan en nuevos concurrentes del mercado, como propone la visión del liberalismo social, a fin de que puedan gozar de la "libertad" que ofrece el mercado y de generar las condiciones para disfrutar de una vida mejor. Un desarrollo humano así deposita en el individuo o en las comunidades pobres la potestad de generar su propio desarrollo, pero sin preocuparse por impulsar cambios estructurales en las relaciones sociales de producción y en las relaciones de poder.

En las condiciones actuales, no pude plantearse el desarrollo humano simplemente como una intentona de dotar a los pobres de 
capacidades y oportunidades, sino que es menester emprender un profundo proceso de reconstrucción de todo el andamiaje estructural, político e institucional que ha sido dañado, desmantelado o destruido por el neoliberalismo. El Estado ha sido secuestrado por el sector corporativo para socavar el fondo de vida de los trabajadores, expoliar grandes parcelas de la recaudación impositiva, apropiarse de sectores económicos estratégicos y preservar la tutela de los intereses corporativos. El compromiso social del Estado y del capital fueron aniquilados, y en su lugar se implementaron estrategias coercitivas y punitivas que han violentado a la sociedad y desgarrado su tejido socioproductivo. Es imperioso, por tanto, reconstruir y reorientar el Estado bajo una agenda social progresista. Lo cual significa, también, intervenir los mercados, que están domeñados por los grandes intereses multinacionales y articular un entramado productivo que revalore el sistema de subsistencia social y genere nuevos mecanismos productivos, financieros y distributivos bajo pautas económicas éticas, responsables y remunerativas, de modo que el trabajo y la naturaleza no se contemplen como mercancías o insumos sometidos a procesos de depredación, sino que se contemplen como los recursos más valiosos para la generación de riqueza, y que su reproducción digna es una meta social primordial.

El movimiento de reconstrucción nacional es una empresa multidimensional que amerita una restauración del tejido social y de las fuerzas productivas, y la formación de capacidades críticas, creativas, productivas y propositivas de las nuevas generaciones para que, inmersas en un cambio cultural, puedan apropiarse del espacio público, revalorar la educación y acceder al mercado laboral en condiciones dignas. La formación político-cultural de las juventudes resulta necesaria para superar la cultura arraigada en el sistema político que promueve el oportunismo, la corrupción y el conservadurismo, todo en aras de un cambio cultural para la transformación social. En el camino de una concientización social y de una organización autónoma e independiente, la eclosión de movimientos sociales liderados por las juventudes representa una renacida esperanza del pueblo de México, frente al embate de los poderes fácticos, las corporaciones rapaces y los políticos corrompidos. 


\section{REFERENCIAS}

Cruz, Antimio (2012), "México, a punto de perder la soberanía alimentaria”, La Crónica: http://www.cronica.com.mx/nota.php?id_ nota $=629555,19$ de enero.

CRUZ, Juan (2012), "Trabajan en la informalidad 60\% de los mexicanos: UNAM", Proceso: http://www.proceso.com.mx/?p=301851, 23 de marzo.

FERnÁNDEZ, Carlos (2012), "Calderón, desbocado", La Jornada:http:// www.jornada.unam.mx/2012/03/29/opinion/036o1eco, 29 de marzo. (2012), "FC: desastre laboral", La Jornada: http://www.jornada. unam.mx/2012/02/09/opinion/028o1eco, 9 de febrero.

Gascón, Verónica (2012), "Crean 400 mil Pymes; quiebra la mitad”, Reforma, 6 de febrero.

GonzÁLEZ, Ixel (2011), "Cae pobreza en AL; repunta en México", El Universal: http://www.eluniversal.com.mx/notas/812554.html, 30 de noviembre.

INEGI (2011), Encuesta Nacional de Ocupación y Empleo, cuarto trimestre de 2011, Aguascalientes, INEGI.

MÁrquez, Humberto (2008), "México en vilo: desmantelamiento de la soberanía laboral y dependencia de las remesas", Papeles de población, vol. 14, no. 58, pp. 73-95.

Márquez, Humberto y Raúl Delgado Wise (2011), "Signos vitales del capitalismo neoliberal: imperialismo, crisis y transformación social", Estudios Críticos del Desarrollo, vol. I, no. 1, pp. 11-50.

MendozA, Antonio (2010), "Financiarización y ganancias de corporaciones en México", Ola financiera, no. 5, pp. 165-197: http://www.olafinanciera.unam.mx/new_web/05/pdfs/Mendoza-OlaFin-5.pdf.

MuÑoz, Carlos y Marisol Silva (2012), "Revertir la desigualdad educativa, un paso decisivo para el desarrollo social" en José Luis Calva (coord.), Políticas de educación, ciencia, tecnología y competitividad, México, Juan Pablos.

OCDE (2011), Estudios económicos de la OCDE. México, OCDE: http://www. pwc.com/es_MX/mx/archivo/2011-05-Estudios-economicos-OCDE.pdf.

PASSEL, Jeffrey S. y D’Vera Cohn (2010), Unauthorized Immigrant Population: National and State Trends, Pew Hispanic Center, Pew Research Center.

RAMírEZ, Erika (2012), "Un cuarto del país en poder de mineras extranjeras", Contralínea: en http://contralinea.info/archivo-revista/index. 
php/2012/01/22/un-cuarto-del-pais-en-poder-de-mineras-extranjeras/, 22 de enero.

RAMÍREZ, Héctor (2012), "Educación superior para un desarrollo incluyente. Tendencias, escenarios, agenda prioritaria" en José Luis Calva (coord.), Políticas de educación, ciencia, tecnología y competitividad, México, Juan Pablos.

Reveles, José (2010), El cártel incómodo. El fin de los Beltrán Leyva y la hegemonía del Chapo Guzmán, México, Grijalbo/Mondadori.

RoDríGUEZ, Israel (2011), "El narcotráfico, el que genera más empleos: 600 mil, afirma experto", La jornada, p. 25, 17 de julio.

Ruiz, Juan Carlos (2012), "México y el día mundial contra la minería a cielo abierto", La Jornada: http://www.jornada.unam.mx/2012/07/21/ opinion/016a1pol, 21 de julio.

SACHER, William (2010), "El modelo minero canadiense: saqueo e impunidad institucionalizados", Acta sociológica, no. 54, enero-abril, pp. 49-67.

UlLOA, Manuel (2012), "Educación básica y media: reformas para el desarrollo" en José Luis Calva (coord.), Políticas de educación, ciencia, tecnología y competitividad, México, Juan Pablos.

UNESCO (2010), Llegar a los marginados. Informe de seguimiento de la EPT en el mundo, París, UNESCO.

Villamil, Jenaro (2009), "Concentración mediática y lavado de cerebros en América Latina”, Sala de prensa, vol. X, no. 5: http://www.saladeprensa.org/art853.htm.

Žižek, Slavoj (2009), Sobre la violencia. Seis reflexiones marginales, Buenos Aires, Paidós.

ZÚÑIGA, Juan (2011), "La deuda externa bruta total de México asciende a 257 mil mdd: BdeM y SHCP", La Jornada: http://www.jornada.unam. $\mathrm{mx} / 2011 / 06 / 10 /$ economia/033n1eco, 10 de junio.

(2012), "El país paga deudas 'contratadas por politicos ladrones': Ferrari”, La Jornada: http://www.jornada.unam.mx/2012/05/09/ economia/022n1eco, 9 de mayo. 
